\title{
The Development of Chinese Language Education in Ireland: \\ Issues and Prospects
}

\author{
Chang Zhang \& Hongfei Wang \\ Trinity Centre for Asian Studies, Trinity College Dublin \\ zhangch@tcd.ie \&wangh5@tcd.ie
}

\begin{abstract}
There has been a massive growth in trade and communication between Ireland and China in the past decade. Under such influence, Irish third level institutions have established Chinese or Chinese-related degree programmes, and postprimary schools have been offering Chinese courses as Transition Year ${ }^{1}$ modules. However, the continuous development of Chinese language education in Ireland also faces many challenges. Though the Junior Cycle Short Course ${ }^{2}$ in Chinese has been designed and published for three years now, there are still very few schools offering this course for a variety of educational and sociocultural reasons. In higher education, Chinese programmes are showing decreasing enrolment, and learners were found to suffer from demotivation issues. This paper briefly reviews the development of Chinese language education in Ireland in the past decade. It aims to suggest means of addressing some existing issues from three general perspectives regarding the course syllabi and materials, the Chinese teachers and the relevant research in an Irish context.
\end{abstract}

Keywords: Ireland, Chinese, Chinese Language Education, Chinese Teaching

\section{Introduction}

According to the 2016 census (CSO, 2017), there were circa ten thousand Chinese immigrants in Ireland who require education in Chinese as a heritage language. The awareness and necessity of learning Chinese as a Foreign Language (CFL) have also been raised in the local Irish community. This has been affected by growing diplomatic, trade and communication links between Ireland and China, which are of increasing importance especially considering the influence of Brexit (Barrett, et al., 2015). To meet such growing demand, policy makers and Chinese educators have been collaborating to develop Chinese language education 
across Irish post-primary and higher education. Since 2007, eight Irish universities and higher education institutions have established degree programmes related to Chinese studies, and over two hundred Irish post-primary schools have introduced Chinese language and culture courses as part of the Transition Year programme (Cai, 2014; Ji, 2015; Wang, 2015; Wu, 2017).

\section{The development of Chinese education in Ireland}

Teaching and Learning Chinese as a Foreign Language (TCFL) has a relatively short history in Ireland, having been around for a little over a decade. The review of its development is provided respectively for two general education sectors (post-primary and higher education), followed by an introduction to the background of Chinese teachers in an Irish context.

\subsection{TCFL in post-primary education}

Affiliated with the Chinese Ministry of Education, the Confucius Institute Headquarters ${ }^{3}$ (also known as Hanban, the Office of Chinese Language Council International) was established in 2004. Its Confucius Institute programme aims to help promote the Chinese language and culture worldwide (Hanban, 2004). Up until 2017, Hanban has established 525 Confucius Institutes and 1113 Confucius Classrooms in 146 countries and regions (Hanban, 2017). As part of a global trend, two Confucius Institutes were founded successively in 2006 in Ireland, which played an important role in helping to develop the awareness of Chinese language and culture in the local community (Wang \& Hao, 2014). With their help, the number of Irish postprimary schools which expressed an interest in conducting Chinese courses started to increase since 2007 (UCD CII, 2012). This growth was strongly supported by Hanban from both financial and human resource perspectives, so that courses were fully funded with teachers allocated directly from China.

As a result, the number of schools which initiated Chinese courses increased from five in 2007 (UCD CII, 2009) to over forty in 2010 (Ruddock, 2010). In 2012, the National Council for Curriculum and Assessment (NCCA) officially launched the Transition Year Unit of Chinese Culture and Language Studies (henceforth abbreviated as TY Chinese module) and publicised a teaching resource package to support teachers conducting the course (NCCA, 2012b). As a result, schools which offered the TY Chinese module increased rapidly to more than two 
hundred within two years (Ji, 2015). However, the TY Chinese module was designed with a predominant focus on cultural studies. The CFL learning occupied only about $10 \%$ of the module and its learning outcome was lower than the Common European Framework of Reference for Languages (CEFR) A1.1 (NCCA, 2012b). As a result, though the TY Chinese module enjoyed popularity, the peripheral nature of the language component in the module means that it did not really have an impact on the TCFL at post-primary level.

Later in 2014, the NCCA launched the Junior Cycle Short Course in Chinese Language and Culture (henceforth abbreviated as Short Course in Chinese). Contrary to the success of the TY Chinese module, not many schools have yet initiated this new course. Firstly, the introduction of the new short courses raised concerns among schools and teachers on the possibility of increased workload due to the new school-based teaching and assessment strategy (RIA, 2016). Secondly, teachers were concerned that the implementation of the new short courses might lead to the reduction of class hours for other existing subjects. Modern Foreign Language (MFL) teachers had a particular concern that other MFL courses may be transformed into short courses when necessary to accommodate the changes of new Junior Cycle curriculum, which may result in reduced course quality (NCCA, 2012a). Thirdly, influenced by the above, the release of relevant supporting documents for the course was delayed. Along with the shortage of qualified Chinese teachers, very few schools have piloted the Short Course in Chinese up to three years after it was published.

Chinese language course enrolment in UK higher education saw a decreased trend in the past few years (UCML \& AULC, 2017). The same trend has begun to develop in Irish higher education while the number of CFL learners at post-primary level was increasing (Ji, 2015). The primary reason is due to the gap between the TCFL in post-primary schools and higher education, which was the absence of the Senior Cycle Chinese courses and the Chinese Leaving Certificate. ${ }^{4}$ As mentioned, though many students were exposed to TY Chinese programmes, the language learning in these programmes was merely a taster. It was often not assessed and not accredited. Without proper Chinese language courses to sustain learners' motivation, it gradually diminished during their Senior Cycle years when students were not exposed to the Chinese language. Learners with genuine interests need to resort to 
private tuition and external exams, such as the Hanyu Shuiping Kaoshi (HSK, the official Chinese proficiency test for non-native speakers), to meet their demand for Chinese learning.

The situation is expected to improve exponentially with the recent change of educational policy. The Irish government has planned to introduce Chinese language into the Leaving Certificate. The 2017 Ireland's Strategy for Foreign Languages in Education (DES, 2017b, p. 16) sets out goals to start implementing Chinese courses in Senior Cycle from 2020, and the first Chinese Leaving Certificate examination is expected to be available in 2022. However, it is necessary to discuss and resolve issues with the Short Course in Chinese to ensure a good foundation for TCFL in Senior Cycle. Moreover, based on the experience of developing Chinese language education in other English speaking countries, such as the UK (Tinsley \& Board, 2014; Zhang \& Li, 2010) and Australia (Bianco, 2007; Orton, 2016), the number of students who would take Chinese Leaving Certificate is presumably small in the early stages, and examinees consist largely of learners who study Chinese as a heritage language in comparison with Irish learners.

\subsection{TCFL in higher education}

Similar to the development of TCFL in a global context, the initiation of TCFL in Irish higher education was partially a reflection of China's economic growth and the longstanding diplomatic ties between the two countries (Xiong \& Grandin, 2010). The first Chinese programme in Irish universities was established in 2006, which was a double major undergraduate degree in commerce and Chinese studies ( $\mathrm{Wu}, 2017)$. Since then, this curriculum design has become the flagship programme of Chinese education for the past decade. After the establishment of the first Chinese programme in Irish universities, undergraduate and postgraduate programmes of Chinese have been introduced in eight Irish universities and higher education institutions (Cai, 2014).

There has been a steady increase in post-beginner CFL learners in Irish higher education in recent years. These students mainly come from three backgrounds. The first category consists of local post-primary school graduates who have learned Chinese in school (e.g., TY Chinese modules, extracurricular courses) or through private tuition. The second category is made up of international students from exchange programmes (e.g., Erasmus), who have studied 
Chinese elsewhere. The final category are the young generations of Chinese immigrants. The majority of the early immigrants from 1950 to 1970 originated from Hong Kong, who are mainly Cantonese speakers. Later in the 1980s, the number of Malaysian Chinese and Chinese from the northeast of China started to increase in Ireland (Yau, 2007). They come from regions that speak different types of Chinese or dialects. Though they and their children demonstrated a strong motivation for pursuing Chinese education, the current Chinese programmes have difficulty in accommodating their diverse needs. This issue has arisen in other English speaking countries when developing Chinese language education, in Australia for example (Wang, et al., 2013). Nevertheless, the future Chinese Leaving Certificate courses will produce more advanced CFL learners entering Irish higher education. With its potential, establishing Chinese as a major is gaining increasing attention from educators in Irish higher education.

As mentioned earlier, the number of CFL learners in Irish higher education decreased over the past few years. After the establishment of the TY Chinese module, there was also a boost in the number of CFL learners in higher education (Wang \& Hao, 2014). However, with initial enthusiasm for the TY Chinese modules wearing off and the absence of a Chinese Leaving Certificate, the enrolment on Chinese programmes in Irish higher education has started to decrease in recent years. In addition, higher education CFL learners were identified as suffering from demotivation, which has led to an increasing dropout rate from Chinese programmes (Zhang \& Wang, 2016a). Chinese programmes with consecutive years of limited enrolment are facing challenges of being merged or suspended.

\subsection{The background of Chinese teachers in Ireland}

The rapid growth of Chinese language education in Ireland should be matched by the qualifications and the Continuing Professional Development (CPD) of Chinese teachers. However, as Chinese is not yet a standard curricular subject in the Irish post-primary education, and as it is therefore not yet possible to register as a teacher of Chinese with the Teaching Council in Ireland, there are as yet no criteria for the qualification of Chinese teachers. 
There are very few Irish teachers who have been teaching Chinese independently across school levels. The common practice for Irish Chinese teachers in post-primary schools is to teach Chinese culture while observing or co-teaching part of the language component with native Chinese teachers (UCD CII, 2013). This worked satisfactorily with the TY Chinese module due to the limited amount of language teaching (Li, 2011; UCD CII, 2013). However, further language training is necessary to meet the increasing demand on teachers' Chinese proficiency required by the Short Course in Chinese and the future Leaving Certificate Chinese courses. Due to the limited number and capacity of Irish Chinese teachers, the current TCFL in Ireland relies predominantly on native Chinese teachers.

As part of Hanban's international Confucius Institute programme (Hanban, 2004), native Chinese teachers are allocated directly from China through the Confucius Institutes and the collaboration of their hosting universities. These teachers can be classified into two general groups, which are the TCFL volunteers and visiting scholars. Most volunteers are TCFL students in Chinese universities. They usually stay for one year as part of their internship programmes, and they are commonly deployed to teach TY Chinese courses. They are passionate about TCFL and are trained in both language teaching theories and cultural demonstration skills. The problem is that the short stay makes it difficult for them to understand and apply local educational philosophy and methodology in their teaching, especially when support by way of CPD has not been adequate ( $W u, 2017)$. The other type of Chinese teacher category is the visiting scholars, who are mainly lecturers in Chinese universities. These lecturers possess more experience in teaching and normally have better communicative capability in English. Their contract with Hanban is normally two to three years, and they are often allocated to teach Chinese courses in higher education. One of the greatest challenges they face is to overcome some inappropriate teaching methods (e.g., teacher-centred classroom) by which they were heavily influenced in a domestic context, in order to meet the demand of higher education MFL courses by Irish standards (Zhang \& Wang, 2016a).

Other than teachers that are associated with Confucius Institutes, there are a further two kinds of native speakers who have been involved in the TCFL in Ireland. Firstly, there are Chinese immigrants who have been teaching in the local community. Some of them are driven 
by survival needs, while others are merely teaching out of their own personal interest. They do not necessarily possess any teaching qualifications, but they are approachable and provide stability for the local community. Through observing their own children's learning experiences in Ireland, they are more familiar with local teaching methodologies in comparison with the above two types of native Chinese teachers. The final category is native Chinese lecturers hired directly by Irish universities. These academics often possess postgraduate degrees in related fields of linguistics or education, but their number is quite small at present.

\section{Discussion on some current issues}

In summary, a central priority for TCFL at post-primary level is the piloting and progress of the Short Course in Chinese, which also affects the further development of Chinese as a Leaving Certificate subject. The issue of CFL learners' demotivation needs to be addressed, which has been causing consistent dropouts in Irish higher education. This section discusses some issues of TCFL in post-primary and higher education respectively from three TCFL standpoints of the Chinese syllabi and teaching materials, the quality and quantity of Chinese teachers and TCFL research in an Irish context.

\subsection{Discussion on issues in post-primary education}

The Short Course in Chinese adopts a school-based teaching and assessment strategy (NCCA, 2016; 2017), which allows teachers to create materials and tailor their courses. However, unlike other established MFL courses, there is a paucity of TCFL resources which could accommodate the needs of foreign learners (Zhang \& Li, 2010). The Chinese textbook Happy Chinese (Chinese for GCSE or Kuaile Hanyu) was widely used for the language teaching in TY Chinese modules as well as some Irish Chinese teacher training programmes (UCD CII, 2013; Wang, 2015). Luo (2012), one of the authors of the book, conducted evaluations of the book and the associated Chinese courses in an Irish context. She pointed out that Chinese teaching materials, as well as the course structure, need to be further localised to meet the needs of Irish learners. Moreover, many of the available TCFL resources come from Chinese websites. The search and utilisation of such resources require a certain level of Chinese proficiency, which many Irish Chinese teachers have not yet achieved. All these problems have increased the difficulty for teachers in compiling and creating materials for their Chinese courses. To 
help schools and teachers to pilot the Short Course in Chinese, guidance on acquiring teaching resources is equally important in comparison with the training of Chinese teaching and assessment.

There are also issues regarding the qualifications of both Irish and Chinese teachers in Ireland. At present, the Chinese language proficiencies of Irish teachers who are involved in TY Chinese modules are still relatively low. It is not sufficient for them to research teaching resources and deliver Chinese courses independently. On the other hand, for native Chinese teachers, an important problem is an insufficient awareness of the challenges that Irish learners face in learning Chinese. The teaching can be teacher-centred and has a lack of communicative elements. This is a common problem which has been reported in many other countries such as New Zealand (Han, 2008, p. 116), Australia (Orton, 2016, p. 373) and the UK (Zhang \& Li, 2010, p. 94). More importantly, these problems will become more critical with the increasing proportion of language teaching required for the Short Course in Chinese and the future Leaving Certificate Chinese courses.

This issue is reflected more among the visiting Chinese teachers. The TCFL training they received in China has still largely derived from the experience of TCFL in a domestic context (Orton, 2010). Due to different student backgrounds and educational philosophies, they need to adapt in order to teach in an Irish context. However, they are often expected to be fully capable of teaching independently by both hosting and receiving units soon after their allocation. This can be quite challenging for many of these teachers, as they only stay for a short period and have no previous teaching experience. They have not been sufficiently supported in terms of necessary time to accommodate to life and teaching in Ireland. More guidance and teaching practice are needed to help them comprehend how to apply the local teaching methods prior to or soon after their teaching. This is extremely important in consideration of the course quality and the sustainability of students' Chinese learning. It is also difficult for schools and institutions to integrate these teachers into their staff system, which has given rise to concerns about the isolation between visiting Chinese teachers and the other local MFL teachers. 
In terms of the number of teachers needed for the Short Course in Chinese and the future Leaving Certificate Chinese courses, it is unrealistic to rely solely on either the local Irish Chinese teachers or the visiting native Chinese teachers. For the Irish Chinese teachers, at present, there are much more profitable career paths than becoming a school teacher. This is part of the bigger problem of the reduced number of students in teacher-training courses in Ireland (O'Brien, 2018). However, the problem is prominent considering the amount of time and effort that need to be invested in learning Chinese. Though there are school teachers who have been learning Chinese and aiming to develop Chinese courses in their schools, the number is far from sufficient. For the visiting Chinese teachers, the number of native Chinese teachers that Confucius Institutes are capable of providing is also unlikely to match the future demand. Hanban allocates teachers based on the submitted annual number of registered Chinese students. Therefore, in advance of any rapid growth in student numbers, it is unlikely the number of their teachers would increase. Meanwhile, the future of Confucius Institutes will be based on a sustainable model whereby they generate their own income (Hanban, 2011). At present, it is still unclear how the Confucius Institutes could manage the cost of the current amount of visiting academic staff after shifting to a self-financing model.

The continuous development of Chinese language education has created increasing demand for TCFL research to support agendas for changes in Irish post-primary education. Many existing issues mentioned previously are closely related to insufficient TCFL research in an Irish context. The goal of a majority of research conducted by visiting Chinese teachers is to improve the Chinese educational system rather than benefit the local TCFL (Ji, 2015; Liu, 2013; Wang \& Hao, 2014). With limited resources and capacity, Chinese researchers in Irish higher education rarely direct their research attention to issues of TCFL in post-primary education. The insufficient support from Chinese research institutions also contributes to the paucity of TCFL research in the Irish context. In comparison with regional and cultural studies, less attention has been given to the problems of the local TCFL. A positive change is that in general, more students and researchers in Irish higher education have started to conduct research targeting the TCFL in an Irish context in recent years. 


\subsection{Discussion on issues in higher education}

The lack of proper teaching materials is one of the most prominent problems for TCFL in Irish higher education (Zhang \& Wang, 2016a) and in a global context (R. Lu, 2017; Zhang \& Li, 2010). Language components and communicative scenarios in Chinese textbooks are often found to be detached from learners' real and local life. In addition to this, there are also problems regarding the design and implementation of the course syllabus. There are Chinese programmes and courses which describe their learning outcomes without any affiliated language standards. General descriptions (e.g., fluent in Chinese speaking) are neither sufficient nor precise, as they vary depending on who makes the reference or does the standardising. The ambiguity affects learners' judgement of their learning outcomes, teachers' choice of materials and pedagogies, and examiners who assess the design and quality of the courses.

Regarding the implementation of language standards, it might be inappropriate to directly apply two existing Chinese standards. The first one is the CEFR, which is the most commonly used benchmark in the European region. However, the CEFR has problems in incorporating the Chinese language into its framework, which is mainly a result of the different logographic writing system and sociocultural background of the Chinese language (EBCL, 2012b). The other standard is the HSK conducted by Hanban. However, as HSK serves both purposes of benchmarking Chinese proficiency and promoting the study of Chinese among foreign learners (Hanban, 2010), language achievements marked by each proficiency level in HSK are relatively low in comparison with the CEFR. Y. Lu (2017) addressed the issue of the criterion validity of the HSK exam in relation to the CEFR standards. The Association of Chinese Teachers in German Speaking Countries pointed out that the vocabulary size required by each level of HSK is only one-third of the equivalent level in CEFR (FACH, 2010). Hsiao and Broeder (2013) expressed concerns about the accuracy of measuring learners' writing skills by both CEFR and HSK. However, it is important to point out that a great proportion of the scholarships which support students to study Mandarin Chinese in universities in mainland China are funded by Hanban. Most of these scholarships demand HSK certificates as a compulsory prerequisite, and the requirement on applicants' Chinese proficiency has increased gradually over the years in response to the growing number of candidates worldwide. 
The appropriateness of the qualifications of native Chinese teachers in Irish higher education also needs to be considered. There is a dearth of qualified Chinese language instructors in Irish higher education in general. Visiting Chinese teachers sent by Confucius Institutes cover a large proportion of the Chinese teaching in Irish higher education, which includes undergraduate and postgraduate Chinese programmes as well as training programmes for post-primary level Chinese teachers. As well as teaching in their hosting universities, these teachers also support other universities and institutions which offer Chinese courses but with a limited capacity of Chinese academic staff. The qualifications of visiting Chinese teachers are approved by Hanban (Hanban, 2017), but not evaluated by the standard of MFL instructors in Irish higher education. This has implications for the quality of Chinese courses in Irish higher education and also the development of Chinese language education in postprimary schools.

From a Chinese teacher and researcher perspective, there is a concern in relation to the balanced role of Chinese academics who are involved in TCFL in Ireland. For example, the primary responsibility for some Chinese Institutions is to establish and promote Chinese programmes. This may cause the recruitment and evaluation criteria of their Chinese academics to be predominantly teaching- or administration-oriented. These academics could be overwhelmed by the teaching and administration workload. They conduct research mainly for personal fulfilment, and face the risks of gradually losing both the capacity and interest for research. This not only causes insufficient TCFL research in an Irish context, but also impacts negatively on the quality of higher education Chinese programmes in the longer term.

Another issue regarding Chinese researchers in Ireland has been the problem of isolation. There has been a lack of communication and cooperation among Chinese educators and researchers in different institutions and across school levels. Chinese teachers in different schools and universities rarely have opportunities to share experiences and resources. Teachers in post-primary schools have not always been familiar with Chinese programmes that are offered in universities, while higher education researchers appeared to be less aware of the issues of TCFL at post-primary level. Chinese teachers and researchers often intentionally or unintentionally isolate themselves from the wider MFL community. There are 
language and sociocultural barriers that Chinese teachers need to overcome, which are essential for their CPD as well as implementing Chinese language education as an organic part of the MFL education in Ireland.

\section{Suggestions for the future}

This section attempts to offer some suggestions for the further development of Chinese language education in both Irish post-primary and higher education. For post-primary education, it focuses on the profile of qualified Chinese teachers and possible directions to address the current shortage of them. For higher education, it provides information on standardising course syllabi and dealing with potential conflicts between syllabi and the requirements of external scholarships. At the end of this section, it calls for more TCFL practitioners and researchers to connect with the wider MFL community in Ireland.

\subsection{Suggestions for TCFL in post-primary education}

The development of post-primary level Chinese language education should be the foundation of TCFL in Ireland. At present, one highly important task is the piloting of the Short Course in Chinese. Training should be arranged to allow interested schools and teachers to become familiar with the course syllabus (NCCA, 2016) and assessment strategies (NCCA, 2017). For native and visiting Chinese teachers, training should focus on Chinese teaching and assessment under the new Junior Cycle framework. For Irish Chinese teachers, proper guidance should also be given on acquiring and adapting suitable teaching and learning resources.

It is still unclear whether Chinese is a designated curricular subject in the new Junior Cycle curricular category, and the Teaching Council has not yet specified what is required to teach the course. The qualification of a teacher is central to the quality and sustainability of the course. One of the key factors that contributed to the success of developing Chinese language education in New Zealand is that both local and migrant Chinese teachers are required to obtain local teaching qualifications prior to their teaching (Han, 2008). It will be necessary to develop a profile for a Short Course in Chinese teacher so that schools and inspectors can properly evaluate the course and so that appropriate training programmes can be developed 
as part of Initial Teacher Education programmes. It will also be important when determining the requirements for teachers of the future Chinese Leaving Certificate, which is certain to be a part of the Senior Cycle curriculum.

There are standards of international TCFL teachers which could be implemented to help identify and recognise the qualification of visiting and migrant Chinese teachers (Orton, 2010). At present, the Irish Teaching Council's requirements for Japanese teachers could be considered as a reference (The Teaching Council, 2013). It regulates the qualification of Japanese teachers in post-primary education from three perspectives of the language proficiency, the experience of cultural studies and the training in educational pedagogy. For language proficiency, teachers should have a minimum of level 2 marked by the Japanese Language Proficiency Test, which is equivalent to CEFR B1 (Okamoto, 2010). The teacher also needs to demonstrate a good knowledge of Japanese culture, which should be included in their training programme. A minimum of six months' experience in a Japanese speaking country or region is also required for non-native speakers. For training experience in educational pedagogy, all registered teachers must have completed a programme of postprimary initial teacher education with a minimum of 120 European Credit Transfer and Accumulation System (ECTS) credits or equivalent.

To address the problem of insufficient qualified Chinese teachers at present and in the following years, it is worth investigating solutions such as shared classes and the assistance of modern educational technology in language education (DES, 2017b, p. 11). As mentioned previously, there are limited numbers of teachers who could cover both the teaching and assessment of the Short Course in Chinese independently. Instead of the conventional way that a single teacher covers several different subjects and bases in one school, it would be more practical to share one Chinese teacher or arrange shared classes among several schools in a region. There are also good practices in using Information and Communication Technology (ICT) tools to increase the quality and feasibility of TCFL in Irish higher education (Zhang \& Wang, 2016b), which could be adapted to the context of post-primary education. 


\subsection{Suggestions for TCFL in higher education}

Regarding the ambiguity of the Chinese syllabi and course descriptions, adaptation is necessary for both benchmarks of the CEFR and the HSK. Institutions which mainly use the CEFR to structure and evaluate their Chinese programmes should take the work of the European Benchmarking for Chinese Languages project as a useful reference (EBCL, 2012a). This project is guided by the Council of Europe to incorporate the Chinese language into the existing CEFR framework. It creates specific criteria for Chinese teaching and examinations in a European context. For the HSK, its certificate is becoming increasingly important for learners who wish to pursue a career or further education in mainland China. Programmes in which students have such intentions should consider introducing or implementing the HSK standard as well to allow students to obtain relevant qualifications for practical benefits.

To address the conflicts between the Chinese course syllabus and external scholarship requirements, several measures could be taken instead of making the course HSK examcentred. The first is to make sure the teachers and students are aware of the different types of scholarships that are available. In addition to the Hanban scholarships, there are also scholarships provided by the Chinese central government, local government, the hosting university and enterprises. Not all the scholarships require Chinese proficiency or HSK certification as a mandatory prerequisite. There are also universities which organise presemester language training programmes to help candidates achieve the required language level for scholarships. The China Scholarship Council publicises such information online to help international students identify scholarships that are available (www.campuschina.org), which should be made known to teachers and students of local Chinese programmes.

The possibility of some internal financial support could also be considered for Chinese students in Irish higher education. Xiang (2017) mentioned using part of the profit from Chinese student exchange programmes to provide internal scholarships and increase the mobility of Chinese learners in a British university. Such a strategy could also be well applied to the Irish context. Institutions with the capacity to establish exchange programmes could consider bridging the TCFL programmes in China with the local Chinese programmes. This may attract more Chinese students to study in Ireland, and also gain extra income for the institution. Part of the income could be reinvested to provide financial support for local 
Chinese learners. The visiting Chinese students would also provide excellent resources for bilingual partnership, which could further enhance the quality of the Chinese programmes.

To solve the problem of isolation between Chinese and other MFL teachers, Chinese teachers should participate more in MFL teaching and learning events instead of focusing exclusively on TCFL. There are some well-established MFL communities which exist across languages, such as the International Association of Applied Linguistics (AILA), the Irish Association for Applied Linguistics (IRAAL) and the regional MFL Communities of Practice organised by the Post-Primary Languages Initiative. Such community and events bring language teachers and researchers together, help share career and subject related information and improve mutual understanding of both theoretical and practical elements. It offers opportunities for other MFL teachers to get in touch with the Chinese teacher community, and boosts collaboration between local and native Chinese teachers. In the context of the 2017 Languages Connect Strategy (DES, 2017a) which specifically references Chinese language education, measures have already started to be taken to address some of the current issues. It is hoped that with the strong support of educational policy, more effort will be put into the continuous development of TCFL by the joint force of TCFL practitioners and researchers in Ireland.

\section{References}

Barrett, A., Bergin, A., FitzGerald, J., Lambert, D., McCoy, D., Morgenroth, E., . . Studnicka, Z. (2015). Scoping the Possible Economic Implications of Brexit on Ireland. Retrieved from https://www.rte.ie/documents/news/esribrexit.pdf

Bianco, J. L. (2007). Emergent China and Chinese: Language Planning Categories. Language Policy, 6(1), 3-26.

Cai, Y. (2014). Integration into the National Education System: The Development of Chinese Teaching in Ireland. International Chinese Teaching and Research, 1(3), 11-12.

CSO. (2017). Census 2016 Summary Results - Part 1. Retrieved from https://pdf.cso.ie/www/pdf/20170601121401_Vital_Statistics_Yearly_Summary_2016 full.pdf

DES. (2017a). Languages Connect: Ireland's Strategy for Foreign Languages in Education 2017-2026. Retrieved from https://www.education.ie/en/Schools-

Colleges/Information/Curriculum-and-Syllabus/Foreign-LanguagesStrategy/fls_languages_connect_implementation_plan.pdf

DES. (2017b). Languages Connect: Ireland's Strategy for Foreign Languages in Education 2017-2026 (Implementation Plan 2017-2022). Retrieved from https://www.education.ie/en/Schools-Colleges/Information/Curriculum-andSyllabus/Foreign-Languages-

Strategy/fls_languages_connect_implementation_plan.pdf 
EBCL. (2012a). EBCL Supporting Documents for Can-Do Statements. Retrieved from http://ebcl.eu.com/wp-content/uploads/2013/02/EBCL-Supporting-Documents-forCDS-Oct-2012.pdf

EBCL. (2012b). European Benchmark Framework for Chinese Final Report. Retrieved from http://eacea.ec.europa.eu/LLp/projects/public_parts/documents/languages/lan_mp_ 511644_EBCLfinal.pdf

FACH. (2010). Statement of The Fachverband Chinesisch e.V. (Association of Chinese Teachers in German Speaking Countries) on The New HSK Chinese Proficiency Test. Retrieved from http://www.fachverbandchinesisch.de/sites/default/files/FaCh2010_ErklaerungHSK_en.pdf

Han, X. (2008). The Issues and Solutions of Chinese Teaching in Post-Primary Schools of New Zealand. Paper presented at the 9th International Conference of Chinese Language Teaching, Beijing, China.

Hanban. (2004). Constitution and By-Laws of the Confucius Institutes. Retrieved from http://english.hanban.org/node_7880.htm

Hanban. (2010). HSK Exam Syllabus. Retrieved from http://www.chinesetest.cn/userfiles/file/dagang/HSK1.pdf

Hanban. (2011). 2011 European Confucius Institutes Working Symposium Reference Materials. Retrieved from http://www.conference.confuciusinstitutes.eu/pdf/reference.pdf

Hanban. (2017). 2017 Confucius Institute Annual Development Report. Retrieved from http://www.hanban.org/report/2017.pdf

Hsiao, Y. P. A., \& Broeder, P. (2013). Applying the Writing Scales of the Common European Framework of Reference for Languages to the New HSK Test of Proficiency in Chinese: Realities, Problems and Some Suggestions for Chinese Language Teachers and Learners. Language Learning in Higher Education, 2(1), 59-74.

Ji, L. (2015). Conceptions and Applications of Chinese Culture Teaching Localization: A Case Study of Ireland. The Science Education Article Collects, 314(14), 39-41.

$\mathrm{Li}, \mathrm{X}$. (2011). Survey on Chinese Language and Culture Learning \& Teaching Program in Irish Secondary Schools. The Guide of Science \& Education, 2011(2), 195-196.

Liu, W. (2013). A Contrastive Study on Irish Transition Year (TY) Education and Chinese Secondary Education. Journal of Tianjin Normal University (Elementary Education Edition), 14(3), 61-64.

Lu, R. (2017). Problematising Identity Work in CFL Teaching Materials. In Y. Lu (Ed.), Teaching and Learning Chinese in Higher Education: Theoretical and Practical Issues (pp. 71-94). Abingdon, UK: Routledge.

Lu, Y. (2017). Exploring the Criterion-Validity of HSK Levels 3 and 4: Are Assessments and CEFR Standards Related? In Y. Lu (Ed.), Teaching and Learning Chinese in Higher Education: Theoretical and Practical Issues (pp. 35-56). Abingdon, UK: Routledge.

Luo, Q. (2012). The Localisation of Chinese Curriculum: From the Present Situation of Foreign Language Teaching in Irish Secondary Schools. Newsletter of the International Society for Chinese Language Teaching, 16(3).

NCCA. (2012a). Senior Cycle Short Courses: Report on the Consultation. Retrieved from https://www.ncca.ie/en/resources/senior_cycle_short_courses_report_on_the_consu Itation_.pdf

NCCA. (2012b). Transition Unit: Chinese Culture and Language Studies. Retrieved from http://ncca.ie/en/Curriculum_and_Assessment/Post- 
Primary_Education/Senior_Cycle/Overview-of-Senior-

Cycle/Transition_Year/Transition_Units/Chinese_Culture_and_Language_Studies.pdf NCCA. (2016). Short Course Chinese Language and Culture: Specification for Junior Cycle Short Course. Retrieved from http://www.curriculumonline.ie/getmedia/c74d14b1ce78-4aa1-b7a6-cd14a7d7dd5a/NCCA-JC-Short-Course-Chinese.pdf

NCCA. (2017). Junior Cycle Chinese Language and Culture Short Course: Guidelines for the Classroom-Based Assessment. Retrieved from http://www.curriculumonline.ie/getmedia/9b006069-bc97-4a27-87d5f3526e91c70b/Chinese_AssessmentGuidelines_Feb2017.pdf

O'Brien, C. (2018, Jan 8). 'Collapse' in Numbers Applying for Teacher-Training Courses. The Irish Times. Retrieved from https://www.irishtimes.com/news/education/collapse-innumbers-applying-for-teacher-training-courses-1.3347607

Okamoto, S. (2010). Common European Framework of Reference Suggests the Sociolinguistic Competence in Teaching Japanese as a Foreign Language. Proceedings of the Hokkaido Bunkyo University Papers(11), 85-98.

Orton, J. (2010). Educating Chinese Language Teachers: Some Fundamentals. In L. Tsung \& K. Cruickshank (Eds.), Teaching and Learning Chinese in Global Contexts: CFL Worldwide (pp. 151-164). London, England: Continuum.

Orton, J. (2016). Issues in Chinese Language Teaching in Australian Schools. Chinese Education \& Society, 49(6), 369-375.

RIA. (2016). Response to the National Council for Curriculum and Assessment's Draft Specification for Junior Cycle Modern Foreign Languages. Retrieved from https://www.ria.ie/sites/default/files/ria_response_-_languages.pdf

Ruddock, K. (2010). Learning from Experience: The Feasibility of Mandarin Chinese in Irish Post-Primary Schools. Post-Primary Languages Initiative.

The Teaching Council. (2013). Teaching Council Registration Post-Primary Curricular Subject Requirements. Retrieved from https://www.teachingcouncil.ie/en/Publications/Registration/Documents/CurricularSubject-Requirments-after-January-2017.pdf

Tinsley, T., \& Board, K. (2014). The Teaching of Chinese in the UK. Retrieved from https://www.britishcouncil.org/sites/default/files/alcantara_full_report_jun15.pdf

UCD CII. (2009). Demand for Mandarin Chinese Teaching in Irish Post-Primary Schools.

UCD CII. (2012). Report on Chinese Culture \& Language Teaching for Transition Year.

UCD CII. (2013). Report on Irish Secondary School Teachers Training Programme.

UCML \& AULC. (2017). Survey of Institution-Wide Language Provision in Universities in the UK (2016-2017). Retrieved from http://www.aulc.org/wpcontent/uploads/2017/10/UCML_AULC_2016-2017.pdf

Wang, D., Moloney, R., \& Li, Z. (2013). Towards Internationalising the Curriculum: A Case Study of Chinese Language Teacher Education Programs in China and Australia. Australian Journal of Teacher Education, 38(9), 116-135.

Wang, X. (2015). The Research of the Present Situation and Countermeasure of Chinese Teaching in Middle Schools in Cork Area of Ireland. (Master's Thesis), Shanghai University, China.

Wang, Z., \& Hao, L. (2014). The Role of Confucius Institutes in Chinese and Foreign Cultural Exchanges: A Case Study on Confucius Institutes in Ireland. Academic Forum, 277(2), 163-166. 
Wu, Q. (2017). A Survey Report on the Chinese-Teaching in College and University in County of Dublin in Ireland. (Master's Thesis), Chongqing Normal University, China.

Xiang, C. H. (2017). Student Mobility as a Language Policy: From Strategy to Practice. Paper presented at the 15th Annual Conference of The British Chinese Language Teaching Society, Southampton University, UK.

Xiong, W., \& Grandin, J. (2010). The Role of Chinese Culture and Language in Global Education. In J. Cai, J. Chen, \& C. Wang (Eds.), Teaching and Learning Chinese: Issues and Perspectives (pp. 199-216). Charlotte, NC: IAP.

Yau, N. (2007). Celtic Tiger, Hidden Dragon: Exploring Identity among Second Generation Chinese in Ireland. Translocations, 2(1), 48-69.

Zhang, C., \& Wang, H. (2016a). Demotivation of Learning Chinese Characters: A Study of Overseas Chinese Learners. In B. Zheng \& Z. Guo (Eds.), Acquisition, Assessment and Application: Theory and Practice of Teaching Chinese in Higher Education (pp. 142151). London, England: Sinolingua London Ltd.

Zhang, C., \& Wang, H. (2016b). Using Digital Textbook to Assist Task-Based Language Learning for Intermediate Level Mandarin Chinese Learners. Retrieved from https://foco.usal.es/en/fichas/using-digital-textbook-to-assist-task-based-languagelearning-for-intermediate-level-mandarin-chinese-learners/ Repositorio FOCO [19-062018].

Zhang, G. X., \& Li, L. M. (2010). Chinese Language Teaching in the UK: Present and Future. Language Learning Journal, 38(1), 87-97.

\footnotetext{
${ }^{1}$ Transition Year is an optional one-year school programme which can be taken in the first year after the Junior Cycle and is compulsory in some schools. It bridges the Junior Cycle and Senior Cycle to complete the six-year cycle of the Irish post-primary level education.

2 The Junior Cycle is the first three years of post-primary level education in Ireland. The Short Courses were introduced in 2014 as part of the Irish Junior Cycle educational reform. Each short course subject is designed to occupy approximately 100 hours in comparison with a minimum of 200 hours for the regular Junior Cycle curriculum subjects.

${ }^{3}$ Confucius Institute is a non-profit public educational organization affiliated with the Ministry of Education of the People's Republic of China. Its institutional role is to promote Chinese language and culture, support local Chinese teaching internationally, and facilitate cultural exchanges.

${ }^{4}$ The Leaving Certificate is the graduate certificate following Senior Cycle study in Irish post-primary level education. It is awarded on the basis of satisfactory completion of examinations organised by the State Examinations Commission, and the results are commonly used as the reference for entry into third level education in Ireland.
} 